Provided for non-commercial research and education use. Not for reproduction, distribution or commercial use.

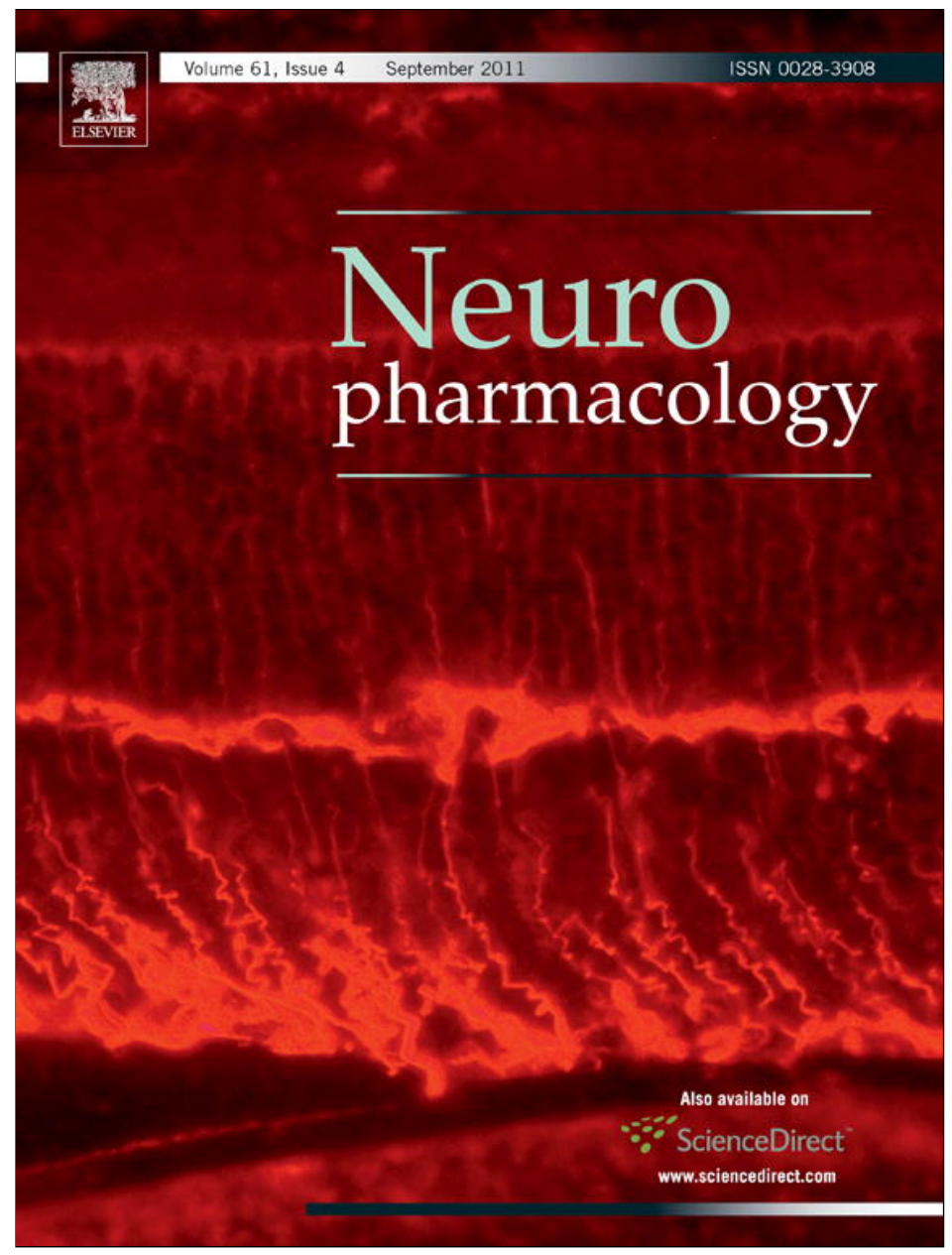

This article appeared in a journal published by Elsevier. The attached copy is furnished to the author for internal non-commercial research and education use, including for instruction at the authors institution and sharing with colleagues.

Other uses, including reproduction and distribution, or selling or licensing copies, or posting to personal, institutional or third party websites are prohibited.

In most cases authors are permitted to post their version of the article (e.g. in Word or Tex form) to their personal website or institutional repository. Authors requiring further information regarding Elsevier's archiving and manuscript policies are encouraged to visit:

http://www.elsevier.com/copyright 


\title{
mGluR2/3 agonist LY379268, by enhancing the production of GDNF, induces a time-related phosphorylation of RET receptor and intracellular signaling Erk1/2 in mouse striatum
}

\author{
Valentina Di Liberto, Giuseppa Mudò ${ }^{1}$, Natale Belluardo*,1 \\ Department of Experimental Medicine and Clinical Neuroscience, University of Palermo, Corso Tukory 129, 90134 Palermo, Italy
}

\section{A R T I C L E I N F O}

\section{Article history:}

Received 5 January 2011

Received in revised form

1 May 2011

Accepted 7 May 2011

\section{Keywords:}

GDNF

RET

mGluR2/3

LY379268

Erk1/2

TrK phosphorylation

\begin{abstract}
A B S T R A C T
In the present study we aimed to verify if the enhancement of glial cell line-derived neurotrophic factor (GDNF) production in mouse striatum following treatment with LY379268 may also induce in the nigrostriatal system a time-related activation of RET receptor and its specific intracellular signaling. For this purpose, we have investigated the effects of LY379268 treatment on RET phosphorylation at the Tyr1062 and on downstream signaling Erk1/2, Akt and PLC $\gamma 1$ pathway activation. The results showed that treatment with LY379268 $(3 \mathrm{mg} / \mathrm{kg})$ induces a significant increase of GDNF levels and time-related RET and Erk1/2 phosphorylation in the striatum. These increases were detected at $24 \mathrm{~h}$ and $48 \mathrm{~h}$ following LY379268 treatment. No changes were observed in the Akt and PLC $\gamma 1$ phosphorylation levels. Similar results for p-Erk1/2 were observed in the substantia nigra. A complete block of LY379268 effect on striatal RET and p-Erk1/2 phosphorylation was observed in mice intrastriatal injected with anti-GDNF antibodies, suggesting a correlation between GDNF upregulation and RET activation. Overall, with present data we have shown that activation of mGluR2/3 receptors by LY379268 may be particularly promising for nigrostriatal dopaminergic system protection by enhancing striatal levels of GDNF/RET trophic system activity.
\end{abstract}

() 2011 Elsevier Ltd. All rights reserved.

\section{Introduction}

Glial cell line-derived neurotrophic factor (GDNF) and its receptors constitute a physiological trophic system in the basal ganglia with critical trophic role for the maturation of dopaminergic neurons, for cell survival and fibre innervations (Li et al., 2006). Following the discovery of GDNF, several studies demonstrated that GDNF protein, infused into the nigral region, is efficacious in reducing or preventing dopaminergic toxicity in rodent models of Parkinson's disease (Beck et al., 1995; Kearns et al., 1997; Tomac et al., 1995a; Soderstrom et al., 2006). In primate model of Parkinson's disease, GDNF protects dopaminergic neurons in the substantia nigra, maintains dopamine levels in striatum, and improves Parkinsonian symptoms (Gash et al., 1996; Costa et al., 2001; Slevin et al., 2005). Several clinical trials using GDNF

Abbreviations: GDNF, glial cell line-derived neurotrophic factor; LY379268, (1R,4R,5S,6R)-4-amino-2-oxabicyclo[3.1.0]hexane-4,6-dic arboxylic acid.

* Corresponding author. Tel.: +39 0916555849; fax: +3909123860714.

E-mail addresses: v.diliberto@unipa.it (V.Di Liberto),g.mudo@unipa.it(G. Mudò), n.belluardo@unipa.it (N. Belluardo).

1 These authors contribute equally to this work. protein intrastriatal infusion were also conducted in Parkinson's disease patients (Kordower et al., 1999; Nutt et al., 2003; Gill et al., 2003; Patel et al., 2005; Slevin et al., 2005), but many of these trials reported several side effects and no improvements of disease. The delivery of GDNF to the central nervous system is challenging because GDNF is unable to cross the blood-brain barrier (Kirik et al., 2004), and several problems also come with GDNF expression induced by viral vectors, or with the use of encapsulated GDNF producing cells (Bespalov and Saarma, 2007). However, since currently GDNF raises great expectations as a potential therapeutic agent for the treatment of Parkinson's disease and other neurodegenerative diseases, the development of drugs that administered systemically may enhance endogenous GDNF expression or activate the GDNF receptor, is an attractive idea as therapeutic option for Parkinson's disease. In this context, recently we reported that treatment with (1R,4R,5S,6R)-4-Amino-2-oxabicyclo[3.1.0]hexane4,6-dic arboxylic acid (LY379268), a selective mGlu2/3 receptor agonist, induces a significant enhancement of striatal GDNF and attenuates the loss of dopaminergic neurons from the substantia nigra in the MPTP mouse model (Battaglia et al., 2009).

In the adult nigrostriatal system endogenous GDNF acts as a target-derived factor for dopaminergic neurons (Tomac et al., 
1995b; Oo et al., 2005) and produces neurotrophic and neuroprotective effects through RET receptor tyrosine kinase and four different glycosylphosphatidylinositol (GPI)-linked receptors (GFR $\alpha 1-4)$. Homodimeric GDNF binds first to monomeric or dimeric GFR $\alpha 1$ and the complex brings two RET molecules together, and tyrosine residues in the intracellular domains of the RET proteins are autophosphorylated (Bespalov and Saarma, 2007; Trupp et al., 1996). Tyrosine autophosphorylation is required for the catalytic activity of RET and for downstream signaling and constitutes the first intracellular event of the RET signaling cascade activated by members of the GDNF ligand family. RET short and middle isoforms contain 16 tyrosine residues in their intracellular domains and RET long isoform has two additional tyrosines in the carboxy-terminal tail. Like other receptor tyrosine kinases, RET can activate different signaling pathways including Ras/Erk, PI3K/Akt, p38/MAPK, PLC $\gamma$ and c-Jun N-terminal kinase (JNK) (Worby et al., 1996; Xing et al., 1998; Chiariello et al., 1998; Trupp et al., 1999; Soler et al., 1999; Hayashi et al., 2000; Takahashi, 2001; Sariola and Saarma, 2003). Among the various tyrosine kinase of RET, it has been demonstrated that Tyr1062 is involved in the activation of Ras/Erk or PI3K/Akt pathways (Besset et al., 2000; Hayashi et al., 2000, 2001; Murakami et al., 1999a, 1999b) and it is required for GDNF-mediated differentiation and survival of neurons (Coulpier et al., 2002; Califano et al., 2000; De Vita et al., 2000; Asai et al., 1996; Besset et al., 2000)

As extension of previous work (Battaglia et al., 2009), in the present study we aimed to verify if the enhancement of GDNF production in mouse striatum following treatment with LY379268 may also induce in the nigrostriatal system a time-related activation of RET receptor and its specific intracellular signaling. For this purpose, we have investigated the effects of LY379268 treatment on RET phosphorylation at the Tyr1062, by using antibodies recognizing the specific phosphorylation of Tyr1062 in the RET receptor, and on downstream signaling Erk1/2 and Akt pathway activation. We focus our attention to RET Tyr1062 since, as above mentioned, it has been involved in GDNF-mediated neuroprotection and neuronal survival and axonal growth (Coulpier et al., 2002) by activation of Ras/Erk or PI3K/Akt pathways.

\section{Material and methods}

\subsection{Animals}

Adult male C57BL6 mice (22-24 g b.w.) from local stock have been used for the present study. The mice were kept under environmentally controlled conditions, ambient temperature $24{ }^{\circ} \mathrm{C}$, humidity $40 \%$ and $12 \mathrm{~h}$ light/dark cycle with food and water ad libitum. Procedures involving animals and their care were conducted in conformity with the institutional guidelines that are in compliance with national (D.L. n. 116,G.U., suppl. 40, 18 Febbraio 1992) and international laws and policies (EEC Council Directive 86/609, OJ L 358,1, Dec. 12, 1987; NIH Guide for the Care and Use of Laboratory Animals, NIH Publication no. 80-23, 1985 and Guidelines for the Use of Animals in Biomedical Research, Thromb. Haemost. 58, 107 8-1084, 1987).

\subsection{Treatments}

Mice were treated with mGluR2/3 selective agonist LY379268 (Tocris Bioscience, Cat. N. 2453), dissolved in saline and administered systemically with a single intraperitoneal (i.p.) injection of $3 \mathrm{mg} / \mathrm{kg}$. Control mice received the same amount of saline. Mice were sacrificed at scheduled time of $24 \mathrm{~h}, 48 \mathrm{~h}$ and $72 \mathrm{~h}$ from treatment. We also used neutralizing goat anti-GDNF antibodies (R\&D Systems Cat.n. AF-212-NA) unilaterally injected into the right striatum. For striatal injection of anti-GDNF antibodies the mice, under anesthesia, were placed in a David Kopf (Tujunga, CA, USA) stereotaxic apparatus and injected using the following stereotaxic coordinates: A5.6, 4.6 and $3.6 \mathrm{~mm}, \mathrm{~L} 1,8$ and V3 mm (Lehmann, 1974). The injection of antibodies was made in three different antero-posterior positions in order to spread the antibodies in a large area of striatum. The dose of neutralizing anti-GDNF antibodies injected in the striatum was $0.5 \mu \mathrm{g}$ in $0.5 \mu \mathrm{l}$ of saline and the following four groups of mice were used: group injected with saline and saline treated; group injected with saline and treated with LY379268 (3 mg/kg i.p.); group injected with neutralizing anti-GDNF antibodies (AF-212-NA, R\&D Systems) and treated with LY379268; group injected with neutralizing anti-GDNF antibodies and saline treated. Following $2 \mathrm{~h}$ of striatal anti-GDNF antibodies injection, all mice groups received saline or LY379268 and were sacrificed $24 \mathrm{~h}$ after the treatment. Mice were killed under deep anaesthesia with chloral hydrate and brains were rapidly removed and striatum and substantia nigra dissected out and immediately frozen on dry ice and stored at $-80{ }^{\circ} \mathrm{C}$. For each experimental condition three independent experiments have been made and each experimental group consisted of at least four mice.

\subsection{GDNF, p-ret, p-Erk1/2, p-akt and p-PLC $\gamma 1$ analysis}

Dissected tissues, striatum and substantia nigra, were homogenized at $4{ }^{\circ} \mathrm{C}$ in a buffer composed of Tris-HCl $50 \mathrm{mM}$ pH 7.4, NaF $50 \mathrm{mM}$, EDTA $2 \mathrm{mM}$, protease inhibitor cocktail (P8340, Sigma-Aldrich S.r.l., Milan, Italy) and phosphatase inhibitor cocktail (P5726, Sigma-Aldrich S.r.l., Milan, Italy). Half of the homogenate was added with Triton X-100 $1 \%$ and SDS $0.1 \%$, left on ice for $30 \mathrm{~min}$ and then centrifuged at $13,000 \mathrm{rpm}$ for $30 \mathrm{~min}$ at $4{ }^{\circ} \mathrm{C}$; The supernatant was stored at $-20^{\circ} \mathrm{C}$, aliquots were taken for protein determination by the method of Lowry et al. 1951 \{LOWRY, 1951 589/id \} and $50 \mu$ g of proteins were used for GDNF, p-Erk1/2, p-Akt and $\mathrm{p}$-PLC $\gamma 1$ western blots. The remaining half of the homogenate was left on ice for $30 \mathrm{~min}$ and then centrifuged at $13,000 \mathrm{rpm}$ for $30 \mathrm{~min}$ at $4{ }^{\circ} \mathrm{C}$; the supernatant, containing cytoplasmatic proteins, was discarded and the pellet instead was homogenized in a buffer composed of Tris- $\mathrm{HCl} 12.5 \mathrm{mM}$ pH 7.4, SDS 0.5\%, EDTA $2 \mathrm{mM}, 1 \mathrm{mM}$ DTT protease inhibitor cocktail (P8340, Sigma-Aldrich S.r.l., Milan, Italy) and phospatase inhibitor cocktail (P5726, Sigma-Aldrich S.r.l., Milan, Italy); the homogenate was left at room temperature for $30 \mathrm{~min}$ and then centrifuged at $13,000 \mathrm{rpm}$ for $30 \mathrm{~min}$ at $4{ }^{\circ} \mathrm{C}$. The supernatant containing membrane proteins was stored at $-20{ }^{\circ} \mathrm{C}$, aliquots were taken for protein determination by the method of Lowry et al. 1951 \{LOWRY, 1951 589/id \} and $50 \mu \mathrm{g}$ of proteins were used for western blotting. The samples and mol. wt. markers (161-0375, Bio-Rad Laboratories S.r.l., Segrate (MI), Italy), were run on $10 \%$ polyacrylamide gel for GDNF and p-Erk1/2, on $8 \%$ polyacrylamide gel for $\mathrm{p}$-Akt and on $6 \%$ polyacrylamide gel for $\mathrm{p}-\mathrm{PLC} \gamma 1$ and $\mathrm{p}$-Ret at $100 \mathrm{~V}$ and electrophoretically transferred onto nitrocellulose membrane (Hybond-C-extra, GE Healthcare, formerly Amersham, Europe GmbH - Filiale Italiana, Milan, Italy). The membranes were incubated for $1 \mathrm{~h}$ in blocking buffer: $1 \times$ TBS, $0.1 \%$ Tween-20, $5 \% \mathrm{w} / \mathrm{v}$ nonfat dry milk. Following three washing for $5 \mathrm{~min}$. with $\mathrm{TBS} / \mathrm{T}$, the membranes were incubated with gentle shaking overnight at $-4{ }^{\circ} \mathrm{C}$ with specific antibody in primary antibody dilution buffer: $1 \mathrm{x}$ TBS, $0.1 \%$ Tween-20, $5 \%$ BSA. The following antibodies were used: anti-GDNF antibody (AF-212-NA, R\&D Systems 1:1000) or anti-phosphorylated Erk1/2 antibody (Rabbit phospho-p44/42 MAPK, Thr202/Tyr204 antibody 1:2000; 9101 Cell Signaling), or antiphosphorylated Akt (rabbit phospho-Akt (Ser473) antibody, 1:1000; 9271 Cell Signaling) or anti-phosphorylated PLC $\gamma 1$ (rabbit phospho-PLC $\gamma 1$ (Tyr783) antibody, 1:1000; 2821 Cell Signaling), or anti-phoshorylated RET using antibody that selectively recognizes phosphorylated RET in Tyr1062 (rabbit p-RET (Tyr1062) antibody 1:1000; sc-20252, Santa Cruz Biotechnology). Following three washing for $5 \mathrm{~min}$ with TBS/T, the membranes were incubated for $1 \mathrm{~h}$ at room temperature with antirabbit IgG horseradish peroxidase-conjugated diluted 1:5000 (Sc, 2004, Santa Cruz Biotechnology) and relative bands were visualized with chemiluminescence reagent (ECL, GE Healthcare, formerly Amersham, Europe GmbH - Filiale Italiana, Milan, Italy) according to the manufacturer's instructions. The blot is exposed to autoradiography film (Amersham Hyperfilm ECL; 28-9068-36), developed in Kodak D19 developer and fixer (Eastman-Kodak, Rochester, NY, USA), and the densitometric evaluation of bands was performed by measuring the optical density using $\mathrm{NIH}$ Image software. For the normalization of quantitative evaluation of bands each membrane was stripped as follow: membranes were incubated at $37^{\circ} \mathrm{C}$ for $30 \mathrm{~min}$ in buffer containing Glicina 200 mM, SDS 3 mM, 1\% of Tween-20, pH 2.2. Following two washing the membranes were reprobed for detection of respective protein by using Rabbit anti-Erk1/2 antibody (9102, Cell Signaling 1:2000), or Rabbit anti-Akt antibody (9272, Cell Signaling 1:1000), or Rabbit anti- PLC $\gamma 1$ antibody (2822, Cell Signaling 1:1000) or Rabbit anti-RET antibody (sc-13104, Santa Cruz Biotechnology 1:500). Mouse anti- $\beta$ actin antibody (sc-47778, Santa Cruz Biotechnolog 1:6000) was used for normalization of GDNF levels and for quantification of total proteins of RET and Erk1/2.

\subsection{Statistical analysis}

The bands on chemiluminescence-sensitive film (Hyperfilm ECL, GE Healthcare, formerly Amersham) from each experiment were scanned using a not selfcalibrating flatbed scanner (Epson Expression 1680 Pro) at a resolution of 1200 dots per inch (dpi). The optical density was assessed using the ImageJ software (Rasband, W.S., ImageJ, U.S. National Institutes of Health, Bethesda, Maryland, USA, http://rsb.info.nih.gov/ij/, 1997-2010), and the results analyzed by Prism 5 software (Graph-Pad, San Diego, CA). The data were then evaluated by one-way ANOVA with intergroup differences analysed by Fisher's Protected Last Significant Difference PLSD test, or by $t$-test analysis. Data, representative of three or four independent experiments with four-five mice for each experimental group, are presented as arbitrary units, or as uncalibrated optical density, and are expressed as mean \pm SEM. 
A
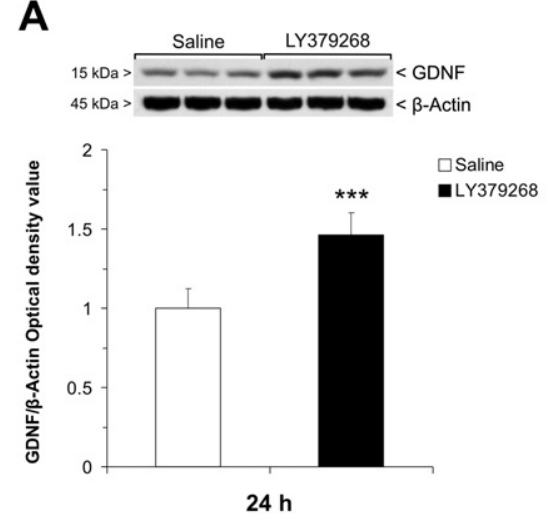

C

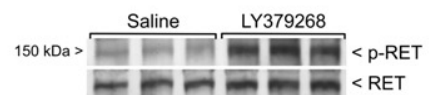

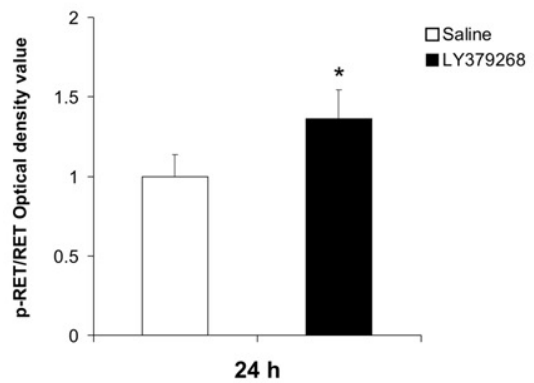

E
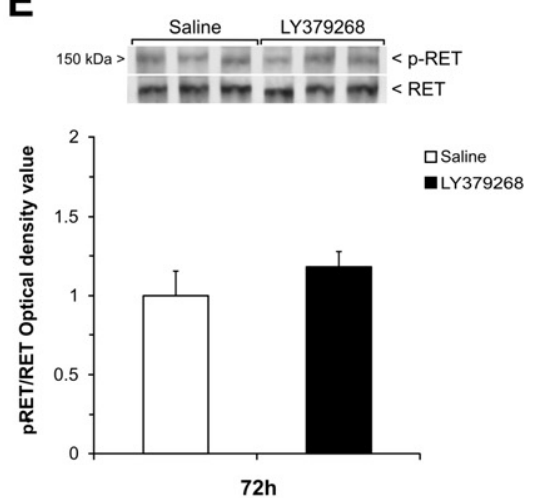

G
B
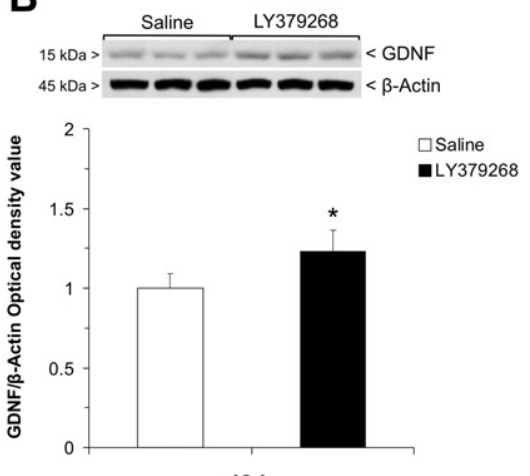

$48 \mathrm{~h}$

D
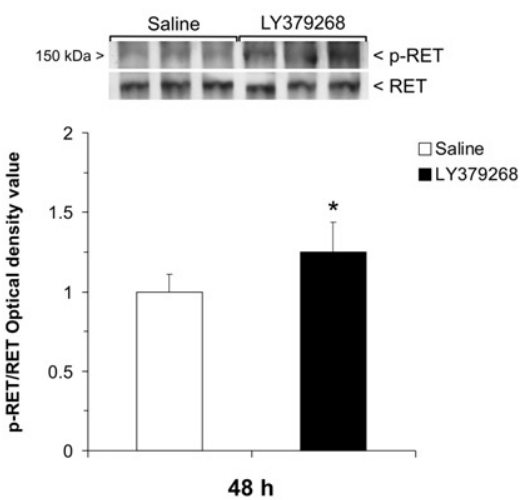

F
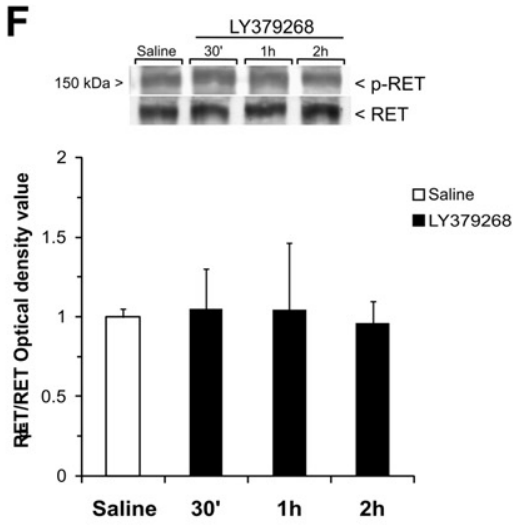

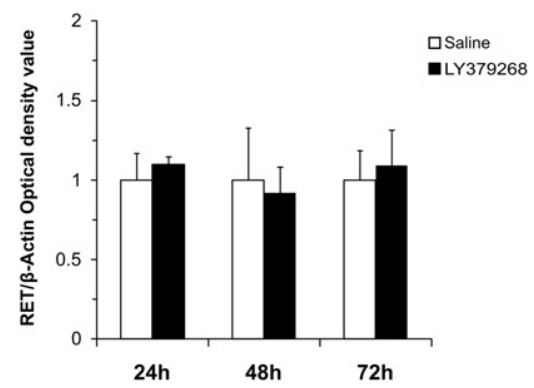

Fig. 1. Western blot analysis of GDNF and p-RET levels in the mouse striatum following LY379268 treatment (3 mg/kg). Data are representative of four independent experiments. (A-B) GDNF $24 \mathrm{~h}$ and $48 \mathrm{~h}$, and (C-E) p-RET levels at $24 \mathrm{~h}, 48 \mathrm{~h}$ and $72 \mathrm{~h}$ from LY379268 treatment. (F) Early time-points of LY379268 treatment effect on p-RET levels. (G) RET protein levels. Histograms express the ratio of band intensity with respect to the loading control. ßactin was used for normalization of GDNF and RET proteins levels. Data are means \pm SEM of optical density (OD) values obtained from films and expressed as arbitrary units. ${ }^{*} P<0.05,{ }^{* * *} P<0.001$. 

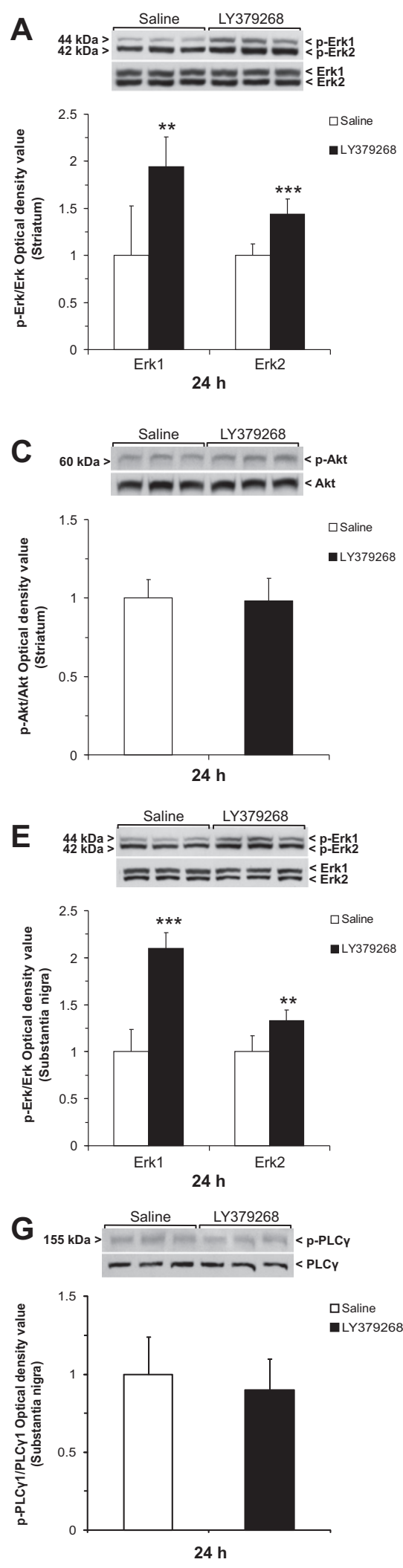
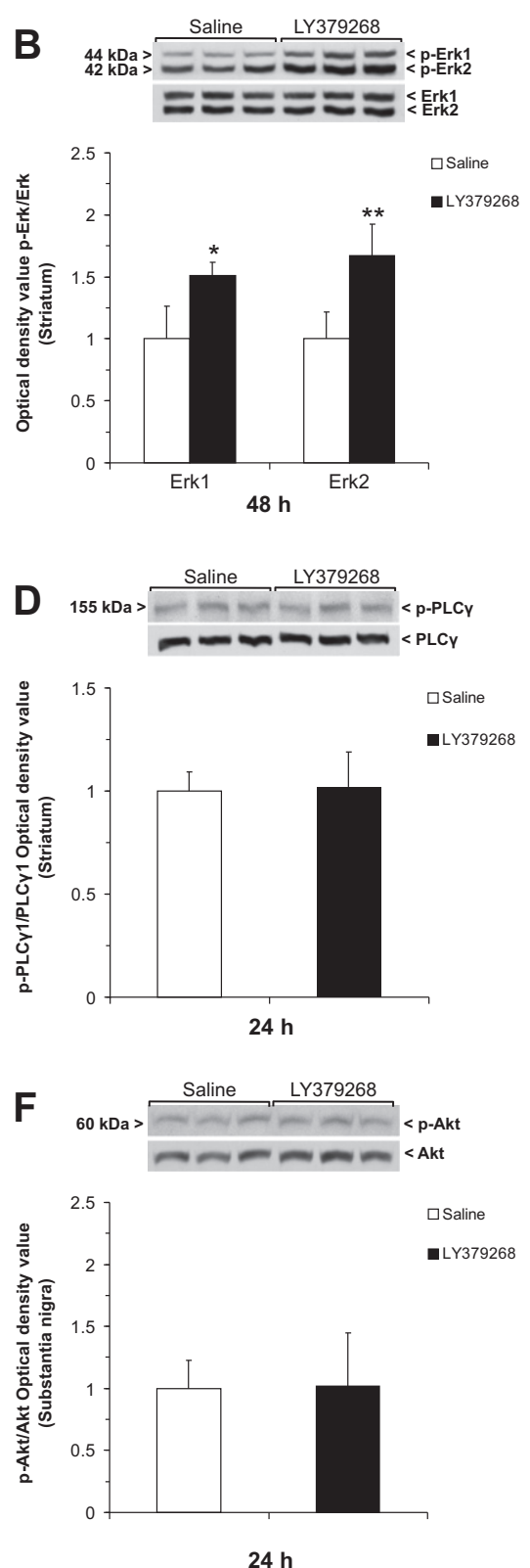

H

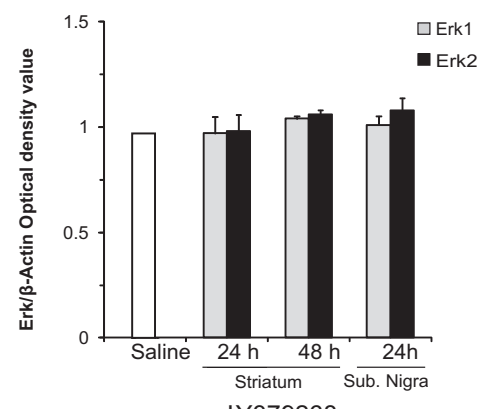

LY379268

Fig. 2. Western blot analysis of p-Erk1/2, p-Akt and p-PLC $\gamma 1$ levels in the mouse striatum and substantia nigra following LY379268 treatment (3 mg/kg). Data are representative of four independent experiments. (A-B) striatal p-Erk1/2 levels at $24 \mathrm{~h}$ and $48 \mathrm{~h}$ from LY379268 treatment; (C) p-Akt and (D) p-PLC $\gamma 1$ levels in the striatum at $24 \mathrm{~h}$ from LY379268 treatment. (E-G) Substantia Nigra p-Erk1/2p-Akt and p-PLC $\gamma 1$ levels at $24 \mathrm{~h}$ from LY379268 treatment. (H) Erk1/2 protein levels. Histograms express the ratio of band intensity with respect to the loading control. ßactin was used for normalization of Erk1/2 protein levels. Data are means \pm SEM of optical density (OD) values obtained from films and expressed as arbitrary units. ${ }^{*} P<0.05,{ }^{* *} P<0.01,{ }^{* * *} P<0.001$. 


\section{Results}

\subsection{Striatal GDNF upregulation following LY379268 treatment}

We first verified the striatal response of GDNF levels to LY379268 treatment using the best conditions revealed in our previous work (Battaglia et al., 2009). Specifically, mice treated with LY379268 (3 mg/kg b.w.) showed an significant increase of striatal GDNF levels both $24 \mathrm{~h}$ and $48 \mathrm{~h}$ following the treatment, as compared to saline control (Fig. 1A-B).

\subsection{RET receptor activation by LY379268 was time-related to GDNF upregulation}

Upon GDNF stimulation, the RET tyrosine kinase receptor is autophosphorylated at a set of cytoplasmic tyrosine residues, among which Tyr1062 in the carboxyl-terminal tail has been found to be critical for GDNF signaling and for the binding of different adaptor molecules (Airaksinen and Saarma, 2002). Here we examined the effects of LY379268 treatment on activation levels of RET Tyr1062 in both substantia nigra and striatum, since RET protein has been found in the mesencephalic dopaminergic neurons and their striatal terminals (Tsuzuki et al., 1995; Glazner et al., 1998; Walker et al., 1998; Honda et al., 1999).

Concerning the striatal analysis, the results showed that treatment with LY379268 (3 mg/kg) induces a significant increase of RET phosphorylation on Tyr 1062 as compared to control saline treated (Fig. 1). This increase of Tyr 1062 activation was detected at $24 \mathrm{~h}$ and $48 \mathrm{~h}$ following LY379268 treatment (Fig. 1C and D) and therefore was time-related to GDNF upregulation in the striatum. The RET phosphorylation levels returned to basal condition at $72 \mathrm{~h}$ from LY379268 treatment (Fig. 1E). No changes were observed in the level of RET protein (Fig. 1G). The time-course of RET activation by LY379268 treatment was extended also to earlier time-points, e.g., $30 \mathrm{~min} ., 1 \mathrm{~h}$, and $2 \mathrm{~h}$, in order to examine the potential activation of RET dependent on acute GDNF release or on its transactivation mediated by mGluR2/3 stimulation. However, the results showed no changes in the RET phosphorylation levels at any time-point examined (Fig. 1F).

The analysis of RET phosphorylation levels in the substantia nigra showed unexpectedly a very low basal RET protein level and the phosphorylated RET on Tyr1062 was undetectable in control mice and apparently not increased following LY379268 treatment (data not shown).

\subsection{RET signaling pathway activation following LY379268}

As above mentioned, RET receptor tyrosine kinase autophosphorylation can activate various signaling pathways including RAS/Erk1/2, PI3K/Akt, PLC $\gamma$, p38 MAPK and JNK pathways (Takahashi, 2001). Particularly, it has been demonstrated that RET phosphorylation at Tyr1062 is indispensable for the activation of the Ras/Erk or PI3K/Akt pathways (Besset et al., 2000) and is required for GDNF-mediated neuroprotection and survival of neurons (Coulpier et al., 2002). Since we found a significant increase of phosphorylated RET on Tyr1062 following LY379268 treatment, we therefore decided to examine the effects of LY379268 treatment on levels of p-Erk1/2 and p-Akt. Additionally we verified the levels of the p-PLC $\gamma 1$ as Tyr1062 independent pathway, and mainly involved in neuronal differentiation.

Phosphorylation levels of p-Erk1/2, p-Akt and p-PLC $\gamma 1$ were investigated both in the striatum and substantia nigra with focus on the best time-point related to upregulation of RET Tyr1062 phosphorylation. The results showed that in the striatum p-Erk1/2 was significantly increased $24 \mathrm{~h}$ and $48 \mathrm{~h}$ after LY379268 treatment
(Fig. 2A and B). There was no significant change in the level of nonphosphorylated forms of ERK demonstrating that the specific activation of ERK is through post-translational modification by phosphorylation rather than regulation of protein expression. By contrast no changes were observed in the Akt (Fig. 2C) and PLC $\gamma 1$ (Fig. 2D) phosphorylation levels in the striatum.

The analysis of p-Erk1/2 levels in the substantia nigra showed, like in the striatum, a significant increase at $24 \mathrm{~h}$ from LY379268 treatment (Fig. 2E). By contrast no changes were observed in the Akt (Fig. 2F) and PLC $\gamma 1$ phosphorylation levels (Fig. 2G).The upregulation of p-Erk1/2 levels was not dependent on change in the Erk1/2 protein levels (Fig. $2 \mathrm{H}$ ).
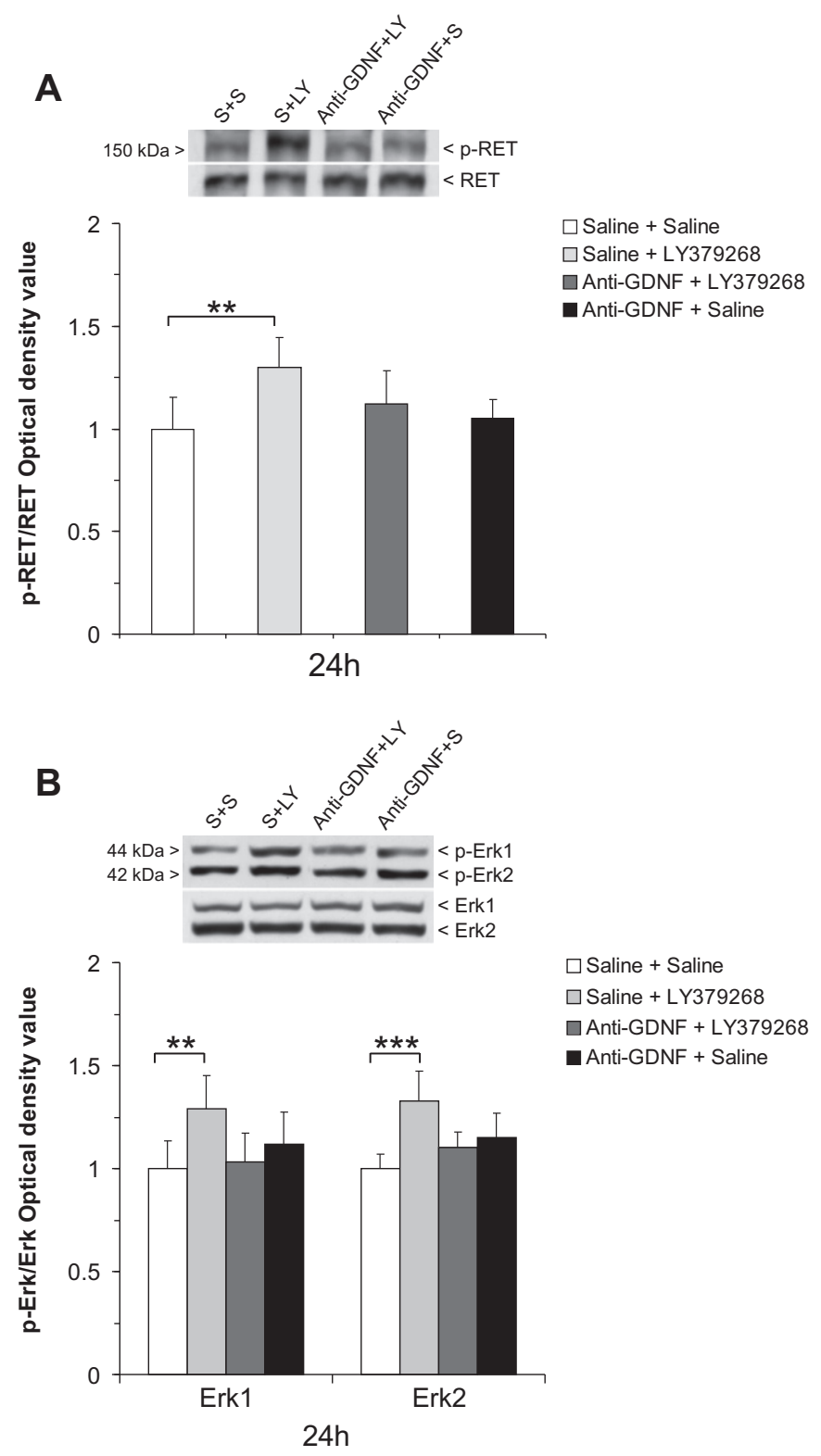

Fig. 3. Western blot analysis of p-RET and p-Erk1/2 levels in mice control or LY379268 treated and in mice preinjected in the right striatum with anti-GDNF antibodies $2 \mathrm{~h}$ before of LY379268 $(3 \mathrm{mg} / \mathrm{kg}$ ) or saline treatment. Data are representative of three independent experiments. (A and B) striatal p-RET and p-Erk1/2 levels at $24 \mathrm{~h}$ from treatment. Histograms express the ratio of band intensity with respect to the loading control. Data are means \pm SEM of optical density (OD) values obtained from films and expressed as arbitrary units. ${ }^{* *} P<0.01,{ }^{* * *} P<0.001$. 
3.4. Correlation between GDNF upregulation and RET activation in the striatum

To examine the causal relationship between the increase in GDNF levels and RET activation, we adopted a similar experimental approach previously developed by Battaglia et al. 2009. We used neutralizing anti-GDNF antibodies unilaterally injected into the right caudate nucleus in order to verify if block of GDNF may abrogate the RET activation and its intracellular signaling. The antiGDNF antibodies injection was made in three different anteroposterior positions in order to spread the antibodies in a large area of striatum. The dose of neutralizing anti-GDNF antibodies was $0.5 \mu \mathrm{g} / 0.5 \mu \mathrm{l}$ of saline for each injection and the following groups of mice were used: group injected with saline and saline treated; group injected with saline and treated with LY379268 $(3 \mathrm{mg} / \mathrm{kg}$ i.p.); group injected with neutralizing anti-GDNF antibodies and treated with LY379268; group injected with neutralizing antiGDNF antibodies and treated with saline. All mice $2 \mathrm{~h}$ after striatal injection received the saline or LY379268 treatment and were sacrificed after $24 \mathrm{~h}$. The results obtained (Fig. 3A) showed a significant block of LY379268-induced RET phosphorylation in the striatum of mice treated with anti-GDNF antibodies, suggesting a correlation between GDNF upregulation by LY379268 treatment and RET activation.

In the same condition, the striatal p-Erk1/2 increase observed following LY379268 treatment was also blocked in mice injected with anti-GDNF antibodies (Fig. 3B), suggesting a functional correlation between RET activation and downstream signaling involving Erk1/2 pathway.

\section{Discussion}

As underlined in the introduction, this work was undertaken in order to extend our previous findings showing the ability of LY379268 to enhance the GDNF levels in the striatum and consequently to be neuroprotective in mouse model of Parkinson's Disease (Battaglia et al., 2009). In the present study we could reveal that the enhancement of GDNF levels in mouse striatum by LY379268 treatment is followed by phosphorylation of RET receptor on Tyr1062 and that Erk1/2 is the intracellular signaling pathway linked to RET activation. In fact, the striatal p-Erk1/2 increase observed following LY379268 treatment was also blocked in mice injected with anti-GDNF antibodies (Fig. 3B), suggesting a functional correlation between RET activation and downstream signaling involving Erk1/2 pathway. Based on this upregulation of p-ERK1/2, although it needs to be further verified, we can speculate that the MAP/ERK pathway may be responsible for GDNF-mediated nigrostriatal neuroprotection observed in the MPTP mouse model of Parkinson's disease (Battaglia et al., 2009).

In the adult striatum, endogenous GDNF expression has been detected only at very low levels and in scattered cells throughout the caudate nucleus, putamen, and internal and external segments of the globus pallidus (Battaglia et al., 2009). The diverse biological actions of GDNF are mediated through its RET receptor tyrosine kinase (Trupp et al., 1996; Yu et al., 1998; Paratcha et al., 2001) and RET protein has been found expressed in the mesencephalic dopaminergic neurons and their striatal terminals, but not in the intrastriatal neurons (Trupp et al., 1997; Golden et al., 1998; Tsuzuki et al., 1995; Glazner et al., 1998; Walker et al., 1998; Honda et al., 1999; He et al., 2008). However, in our hand, it was possible to detect RET protein in the striatum but not in the substantia nigra. These observations suggested that GDNF is functioning as a targetderived factor to maintain dopaminergic neuronal circuits within the basal ganglia (Barroso-Chinea et al., 2005; Tomac et al., 1995b). GDNF binding to RET receptor lead to tyrosine kinase autophosphorylation at a set of 16 cytoplasmic tyrosine residues, in the RET short and middle isoforms, and two additional tyrosines in the carboxy-terminal tail, in the RET long isoform. RET receptor tyrosine kinase autophosphorylation can activate various signaling pathways including RAS/ERK, PI3K/AKT and p38MAPK (Worby et al., 1996; Xing et al., 1998; Chiariello et al., 1998; Trupp et al., 1999; Soler et al., 1999; Hayashi et al., 2000; Takahashi, 2001; Sariola and Saarma, 2003). Particularly, it has been demonstrated that Tyr1062 is involved in the activation of Ras/Erk or PI3K/Akt pathways (Besset et al., 2000; Hayashi et al., 2000, 2001; Murakami et al., 1999a, 1999b) and is required for GDNF-mediated neurons differentiation and survival (Coulpier et al., 2002; Califano et al., 2000; De Vita et al., 2000).

In the present work, the RET phosphorylation on Tyr1062 was found linked with increased activity of Erk1/2 pathway both in the striatum and substantia nigra. By contrast, no changes were observed in the Akt and PLC $\gamma 1$ phosphorylation in both brain regions.

Following neurotrophin stimulation of distal axons, multiple signaling pathways are activated locally within the axons. These include retrograde neurotrophic signaling, which plays a critical role in regulating neuronal growth, survival and differentiation of innervating neurons, and signaling molecules, such as PI3K/Akt, MAPK/Erk1/2 and Erk5 which promote local effects such as axonal outgrowth and synaptic plasticity (Ginty and Segal, 2002). Increasing evidence suggest that endosomes containing neurotrophin/receptor activated complexes and other signaling proteins of the Ras/Erk1/2, p38MAPK, and PI3K/Akt pathways serve as an important source of neurotrophic retrograde signals (Wu et al., 2009; Ginty and Segal, 2002; Coulpier and Ibanez, 2004). Using an in vitro model, GDNF stimulation of distal axons resulted in activation of downstream signaling of Erk1/2 and Akt phosphorylation in the axons, and RET and Akt phosphorylation in the cell bodies, demonstrating the retrograde propagation of an intracellular GDNF-mediated signal (Coulpier and Ibanez, 2004; Tomac et al., 1995b). A retrograde propagation of GDNF signaling is also supported by data showing Erk1/2 activation in the substantia nigra following striatal GDNF injection (Salvatore et al., 2004; Lindgren et al., 2008). In the present study, following LY379268 treatment Erk1/2 signaling pathway was found significantly activated also in the substantia nigra.

Although the increased levels of phosphorylated RET were found time-related to GDNF protein upregulation, in order to verify the direct link between LY379268-induced GDNF and the RET activation we adopted the strategy based on the injection of neutralizing anti-GDNF antibodies in the striatum. The injection of anti-GDNF antibodies in the striatum was significantly able to block the effects of LY379268 on RET and Erk1/2 activation in the striatum, suggesting a GDNF-dependent RET phosphorylation following LY379268 treatment. This approach was also successful in a previous paper, where we could show that LY379268 treatment loses its neuroprotective activity after anti-GDNF antibodies implantation in the striatum (Battaglia et al., 2009). However, following LY379268 treatment we could not observe a complete block of RET phosphorylation probably because the neutralizing anti-GDNF antibodies injection in three striatal position was not enough to cover all the striatum.

The activation of mGluR $2 / 3$ have been implicated in the production of other neurotrophic factors, such as TGF $\beta 1$ in astrocytes (Bruno et al., 1998; Ciccarelli et al., 1997) and in the striatum (D’Onofrio et al., 2001), or BDNF in microglia (Matarredona et al., 2001; Venero et al., 2002), in the hippocampus (Di Liberto et al., 2010), in neuronal hippocampal cultures (Canossa et al., 2001; Wu et al., 2004; Marini et al., 1998) and in reactive astrocytes (Mudo et al., 2007; Ohishi et al., 1993, 1998). Although this proved 
involvement of mGluR2/3 in neurotrophic factors regulation, the present data, together with previous related findings (Battaglia et al., 2009), provide a complete demonstration for an involvement of GDNF/RET neurotrophic system in the neuroprotection observed in the mouse model of Parkinson's disease following mGluR2/3 activation.

GDNF and its receptor constitute a physiological trophic system in the basal ganglia with critical trophic role for the maturation of dopaminergic neurons, for cell survival and fibre innervations (Li et al., 2006). GDNF has been evaluated in several clinical trials for its effect on Parkinson's disease (Kordower et al., 1999; Gill et al., 2003; Slevin et al., 2005; Lang et al., 2006), according with its consistent neuroprotective and restoring activity in experimental models of parkinsonism. The major limitation associated with the peripheral administration of GDNF as therapy for neurodegenerative disorders and brain injury is the poor penetration across the blood-brain barrier. Therefore, the use of low-molecular weight drugs, such as LY379268, that administered systemically may enhance endogenous GDNF/RET neurotrophic system is relevant in order to overcome most of the problems associated with the delivery of GDNF protein into the brain. Therefore, with the present results we contributed to reveal the possibility that pharmacological activation of mGluR2/3 may slow the progression of neurodegenerative disorders through the mechanism based on the production of endogenous GDNF/RET neurotrophic system.

\section{Conclusions}

Overall, with previous (Battaglia et al., 2009) and present data we have shown that activation of mGluR2/3 receptors by LY379268 is particularly promising for the experimental treatment of Parkinson's disease, since it may protect nigrostriatal dopaminergic system by enhancing striatal levels of GDNF/RET trophic system activity.

\section{Acknowledgments}

This work was supported by grants of MIUR (Prin 2007, 200728AA57_004); Progetti di Ateneo (Università di Palermo). DLV, supported by Ateneo of Palermo doctorate in "Scienze dell'attività motoria".

\section{References}

Airaksinen, M.S., Saarma, M., 2002. The GDNF family: signalling, biological functions and therapeutic value. Nat Rev Neurosci. 3, 383-394.

Asai, N., Murakami, H., Iwashita, T., Takahashi, M., 1996. A mutation at tyrosine 1062 in MEN2A-Ret and MEN2B-Ret impairs their transforming activity and association with shc adaptor proteins. J. Biol. Chem. 271, 17644-17649.

Barroso-Chinea, P., Cruz-Muros, I., Aymerich, M.S., Rodriguez-Diaz, M., AfonsoOramas, D., Lanciego, J.L., Gonzalez-Hernandez, T., 2005. Striatal expression of GDNF and differential vulnerability of midbrain dopaminergic cells. Eur J. Neurosci. 21, 1815-1827.

Battaglia, G., Molinaro, G., Riozzi, B., Storto, M., Busceti, C.L., Spinsanti, P., Bucci, D., Di, L.V., Mudo, G., Corti, C., Corsi, M., Nicoletti, F., Belluardo, N., Bruno, V., 2009. Activation of mGlu3 receptors stimulates the production of GDNF in striatal neurons. PLoS One 4 e6591.

Beck, K.D., Valverde, J., Alexi, T., Poulsen, K., Moffat, B., Vandlen, R.A., Rosenthal, A. Hefti, F., 1995. Mesencephalic dopaminergic neurons protected by GDNF from axotomy-induced degeneration in the adult brain. Nature 373, 339-341.

Bespalov, M.M., Saarma, M., 2007. GDNF family receptor complexes are emerging drug targets. Trends Pharmacol. Sci. 28, 68-74.

Besset, V., Scott, R.P., Ibanez, C.F., 2000. Signaling complexes and protein-protein interactions involved in the activation of the Ras and phosphatidylinositol 3-kinase pathways by the c-Ret receptor tyrosine kinase. J. Biol. Chem. 275, 39159-39166.

Bruno, V., Battaglia, G., Casabona, G., Copani, A., Caciagli, F., Nicoletti, F., 1998. Neuroprotection by glial metabotropic glutamate receptors is mediated by transforming growth factor-beta. J. Neurosci. 18, 9594-9600.

Califano, D., Rizzo, C., D’Alessio, A., Colucci-D’Amato, G.L., Cali, G., Bartoli, P.C., Santelli, G., Vecchio, G., de Franciscis, F.V., 2000. Signaling through Ras is essential for ret oncogene-induced cell differentiation in PC12 cells. J. Biol. Chem. 275, 19297-19305.
Canossa, M., Gartner, A., Campana, G., Inagaki, N., Thoenen, H., 2001. Regulated secretion of neurotrophins by metabotropic glutamate group I (mGluRI) and Trk receptor activation is mediated via phospholipase $C$ signalling pathways. EMBO J. 20, 1640-1650.

Chiariello, M., Visconti, R., Carlomagno, F., Melillo, R.M., Bucci, C., de, F.V., Fox, G.M., Jing, S., Coso, O.A., Gutkind, J.S., Fusco, A., Santoro, M., 1998. Signalling of the Ret receptor tyrosine kinase through the c-Jun NH2-terminal protein kinases (JNKS): evidence for a divergence of the ERKs and JNKs pathways induced by Ret. Oncogene 16, 2435-2445.

Ciccarelli, R., Sureda, F.X., Casabona, G., Di, I.P., Caruso, A., Spinella, F., Condorelli, D.F., Nicoletti, F., Caciagli, F., 1997. Opposite influence of the metabotropic glutamate receptor subtypes mGlu3 and -5 on astrocyte proliferation in culture. Glia 21, 390-398.

Costa, S., Iravani, M.M., Pearce, R.K., Jenner, P., 2001. Glial cell line-derived neurotrophic factor concentration dependently improves disability and motor activity in MPTP-treated common marmosets. Eur. J. Pharmacol. 412, 45-50.

Coulpier, M., Ibanez, C.F., 2004. Retrograde propagation of GDNF-mediated signals in sympathetic neurons. Mol. Cell. Neurosci. 27, 132-139.

Coulpier, M., Anders, J., Ibanez, C.F., 2002. Coordinated activation of autophosphorylation sites in the RET receptor tyrosine kinase: importance of tyrosine 1062 for GDNF mediated neuronal differentiation and survival. J. Biol. Chem. 277, 1991-1999.

D’Onofrio, M., Cuomo, L., Battaglia, G., Ngomba, R.T., Storto, M., Kingston, A.E. Orzi, F., De, B.A., Di, I.P., Nicoletti, F., Bruno, V., 2001. Neuroprotection mediated by glial group-II metabotropic glutamate receptors requires the activation of the MAP kinase and the phosphatidylinositol-3-kinase pathways. J. Neurochem. 78, 435-445.

De Vita, G., Melillo, R.M., Carlomagno, F., Visconti, R., Castellone, M.D., Bellacosa, A. Billaud, M., Fusco, A., Tsichlis, P.N., Santoro, M., 2000. Tyrosine 1062 of RETMEN2A mediates activation of Akt (protein kinase B) and mitogen-activated protein kinase pathways leading to PC12 cell survival. Cancer Res. 60, 3727-3731.

Di Liberto, V., Bonomo, A., Frinchi, M., Belluardo, N., Mudo, G., 2010. Group I metabotropic glutamate receptor activation by agonist LY379268 treatment increases the expression of brain derived neurotrophic factor in the mouse brain. Neuroscience $165,863-873$.

Gash, D.M., Zhang, Z., Ovadia, A., Cass, W.A., Yi, A., Simmerman, L., Russell, D. Martin, D., Lapchak, P.A., Collins, F., Hoffer, B.J., Gerhardt, G.A., 1996. Functional recovery in parkinsonian monkeys treated with GDNF. Nature 380 , 252-255.

Gill, S.S., Patel, N.K., Hotton, G.R., O'Sullivan, K., McCarter, R., Bunnage, M. Brooks, D.J., Svendsen, C.N., Heywood, P. 2003. Direct brain infusion of glial cell line-derived neurotrophic factor in Parkinson disease. Nat. Med. 9, 589-595.

Ginty, D.D., Segal, R.A., 2002. Retrograde neurotrophin signaling: Trk-ing along the axon. Curr. Opin. Neurobiol. 12, 268-274.

Glazner, G.W. Mu, X. Springer, J.E., 1998, Localization of glial cell line-derived neurotrophic factor receptor alpha and c-ret mRNA in rat central nervous system. J. Comp. Neurol. 391, 42-49.

Golden, J.P., Baloh, R.H., Kotzbauer, P.T., Lampe, P.A., Osborne, P.A., Milbrandt, J. Johnson Jr., E.M., 1998. Expression of neurturin, GDNF, and their receptors in the adult mouse CNS. J. Comp. Neurol. 398, 139-150.

Hayashi, H., Ichihara, M., Iwashita, T., Murakami, H., Shimono, Y., Kawai, K., Kurokawa, K., Murakumo, Y., Imai, T., Funahashi, H., Nakao, A., Takahashi, M., 2000. Characterization of intracellular signals via tyrosine 1062 in RET activated by glial cell line-derived neurotrophic factor. Oncogene 19, 4469-4475.

Hayashi, Y., Iwashita, T., Murakamai, H., Kato, Y., Kawai, K., Kurokawa, K., Tohnai, I., Ueda, M., Takahashi, M., 2001. Activation of BMK1 via tyrosine 1062 in RET by GDNF and MEN2A mutation. Biochem. Biophys. Res. Commun. 281, 682-689.

He, S.M., Zhao, Z.W., Zhao, L., Wang, X.L., Jia, D., Hou, F., Gao, G.D., 2008. Nigrostriatal projecting neurons express GDNF receptor subunit RET in adult rats. Acta Neurobiol. Exp. (Wars) 68, 347-353.

Honda, T., Takahashi, M., Sugiura, Y., 1999. Co-localization of the glial cell-line derived neurotrophic factor and its functional receptor c-RET in a subpopulation of rat dorsal root ganglion neurons. Neurosci. Lett. 275, 45-48.

Kearns, C.M., Cass, W.A., Smoot, K., Kryscio, R., Gash, D.M., 1997. GDNF protection against 6-OHDA: time dependence and requirement for protein synthesis. J. Neurosci. 17, 7111-7118.

Kirik, D., Georgievska, B., Bjorklund, A., 2004. Localized striatal delivery of GDNF as a treatment for Parkinson disease. Nat. Neurosci. 7, 105-110.

Kordower, J.H., Palfi, S., Chen, E.Y, Ma, S.Y., Sendera, T, Cochran, EJ., Cochran, E. Mufson, E.J., Penn, R., Goetz, C.G., Comella, C.D., 1999. Clinicopathological findings following intraventricular glial-derived neurotrophic factor treatment in a patient with Parkinson's disease. Ann. Neurol. 46, 419-424.

Lang, A.E., et al., 2006. Randomized controlled trial of intraputamenal glial cell linederived neurotrophic factor infusion in Parkinson disease. Ann. Neurol. 59, 459-466.

Lehmann, A., 1974. Atlas Stéréotaxique du Cerveau de la Souris. Éditions du Centre National de la Recherche Scientifique.

Li, L., Su, Y., Zhao, C., Zhao, H., Liu, G., Wang J., Xu, O, 2006. The role of Ret receptor tyrosine kinase in dopaminergic neuron development. Neuroscience 142, 391-400.

Lindgren, N., Leak, R.K., Carlson, K.M., Smith, A.D., Zigmond, M.J., 2008. Activation of the extracellular signal-regulated kinases 1 and 2 by glial cell line-derived neurotrophic factor and its relation to neuroprotection in a mouse model of Parkinson's disease. J. Neurosci. Res. 86, 2039-2049.

Lowry, O.H., Rosebrough, N.J., Farr, A.L., Randall, R.J., 1951. Protein measurement with the Folin phenol reagent. J. Biol. Chem. 193, 265-275. 
Marini, A.M., Rabin, S.J., Lipsky, R.H., Mocchetti, I., 1998. Activity-dependent release of brain-derived neurotrophic factor underlies the neuroprotective effect of $\mathrm{N}$ methyl-D-aspartate. J. Biol. Chem. 273, 29394-29399.

Matarredona, E.R., Santiago, M., Venero, J.L., Cano, J., Machado, A., 2001. Group II metabotropic glutamate receptor activation protects striatal dopaminergic nerve terminals against MPP+-induced neurotoxicity along with brain-derived neurotrophic factor induction. J. Neurochem. 76, 351-360.

Mudo, G., Trovato-Salinaro, A., Caniglia, G., Cheng, Q., Condorelli, D.F., 2007. Cellular localization of mGluR3 and mGluR5 mRNAs in normal and injured rat brain. Brain Res. 1149, 1-13

Murakami, H., Iwashita, T., Asai, N., Iwata, Y., Narumiya, S., Takahashi, M., 1999a. Rho-dependent and -independent tyrosine phosphorylation of focal adhesion kinase, paxillin and p130Cas mediated by Ret kinase. Oncogene 18, 1975-1982.

Murakami, H., Iwashita, T., Asai, N., Shimono, Y., Iwata, Y., Kawai, K., Takahashi, M., 1999b. Enhanced phosphatidylinositol 3-kinase activity and high phosphorylation state of its downstream signalling molecules mediated by ret with the MEN 2B mutation. Biochem. Biophys. Res. Commun. 262, 68-75.

Nutt, J.G., Burchiel, K.J., Comella, C.L., Jankovic, J., Lang, A.E., Laws Jr., E.R., Lozano, A.M., Penn, R.D., Simpson Jr., R.K., Stacy, M., Wooten, G.F., 2003. Randomized, double-blind trial of glial cell line-derived neurotrophic factor (GDNF) in PD. Neurology 60, 69-73.

Ohishi, H., Shigemoto, R., Nakanishi, S., Mizuno, N., 1993. Distribution of the messenger RNA for a metabotropic glutamate receptor, mGluR2, in the central nervous system of the rat. Neuroscience 53, 1009-1018.

Ohishi, H., Neki, A., Mizuno, N., 1998. Distribution of a metabotropic glutamate receptor, mGluR2, in the central nervous system of the rat and mouse: an immunohistochemical study with a monoclonal antibody. Neurosci. Res. 30, 65-82.

Oo, T.F., Ries, V., Cho, J., Kholodilov, N., Burke, R.E., 2005. Anatomical basis of glial cell line-derived neurotrophic factor expression in the striatum and related basal ganglia during postnatal development of the rat. J. Comp. Neurol. 484, 57-67.

Paratcha, G., Ledda, F., Baars, L., Coulpier, M., Besset, V., Anders, J., Scott, R., Ibanez, C.F., 2001. Released GFRalpha1 potentiates downstream signaling, neuronal survival, and differentiation via a novel mechanism of recruitment of c-Ret to lipid rafts. Neuron 29, 171-184.

Patel, N.K., Bunnage, M., Plaha, P., Svendsen, C.N., Heywood, P., Gill, S.S., 2005. Intraputamenal infusion of glial cell line-derived neurotrophic factor in PD: a two-year outcome study. Ann. Neurol. 57, 298-302.

Salvatore, M.F., Zhang, J.L., Large, D.M., Wilson, P.E., Gash, C.R., Thomas, T.C., Haycock, J.W., Bing, G., Stanford, J.A., Gash, D.M., Gerhardt, G.A., 2004. Striatal GDNF administration increases tyrosine hydroxylase phosphorylation in the rat striatum and substantia nigra. J. Neurochem. 90, 245-254.

Sariola, H., Saarma, M., 2003. Novel functions and signalling pathways for GDNF. J. Cell Sci. 116, 3855-3862.

Slevin, J.T., Gerhardt, G.A., Smith, C.D., Gash, D.M., Kryscio, R., Young, B., 2005. Improvement of bilateral motor functions in patients with Parkinson disease through the unilateral intraputaminal infusion of glial cell line-derived neurotrophic factor. J. Neurosurg. 102, 216-222.

Soderstrom, K., O'Malley, J., Steece-Collier, K., Kordower, J.H., 2006. Neural repair strategies for Parkinson's disease: insights from primate models. Cell Transplant. 15, 251-265
Soler, R.M., Dolcet, X., Encinas, M., Egea, J., Bayascas, J.R., Comella, J.X., 1999. Receptors of the glial cell line-derived neurotrophic factor family of neurotrophic factors signal cell survival through the phosphatidylinositol 3-kinase pathway in spinal cord motoneurons. J. Neurosci. 19, 9160-9169.

Takahashi, M., 2001. The GDNF/RET signaling pathway and human diseases. Cytokine Growth Factor Rev. 12, 361-373.

Tomac, A., Lindqvist, E., Lin, L.F., Ogren, S.O., Young, D., Hoffer, B.J., Olson, L., 1995a. Protection and repair of the nigrostriatal dopaminergic system by GDNF in vivo. Nature 373, 335-339.

Tomac, A., Widenfalk, J., Lin, L.F., Kohno, T., Ebendal, T., Hoffer, B.J., Olson, L., 1995b. Retrograde axonal transport of glial cell line-derived neurotrophic factor in the adult nigrostriatal system suggests a trophic role in the adult. Proc. Natl. Acad. Sci. U S A 92, 8274-8278.

Trupp, M., Arenas, E., Fainzilber, M., Nilsson, A.S., Sieber, B.A., Grigoriou, M., Kilkenny, C., Salazar-Grueso, E., Pachnis, V., Arumae, U., 1996. Functional receptor for GDNF encoded by the c-ret proto-oncogene. Nature 381, 785-789.

Trupp, M. Belluardo, N. Funakoshi, H. Ibanez, C.F, 1997. Complementary and overlapping expression of glial cell line-derived neurotrophic factor (GDNF), c-ret proto-oncogene, and GDNF receptor-alpha indicates multiple mechanisms of trophic actions in the adult rat CNS. J. Neurosci. 17, 3554-3567.

Trupp, M., Scott, R., Whittemore, S.R., Ibanez, C.F., 1999. Ret-dependent and -independent mechanisms of glial cell line-derived neurotrophic factor signaling in neuronal cells. J. Biol. Chem. 274, 20885-20894.

Tsuzuki, T., Takahashi, M., Asai, N., Iwashita, T., Matsuyama, M., Asai, J., 1995. Spatial and temporal expression of the ret proto-oncogene product in embryonic, infant and adult rat tissues. Oncogene 10,191-198.

Venero, J.L., Santiago, M., Tomas-Camardiel, M., Matarredona, E.R., Cano, J., Machado, A., 2002. DCG-IV but not other group-II metabotropic receptor agonists induces microglial BDNF mRNA expression in the rat striatum. Correlation with neuronal injury. Neuroscience 113, 857-869.

Walker, D.G, Beach, T.G., Xu, R., Lile, J., Beck, K.D., McGeer, E.G., McGeer, P.L, 1998. Expression of the proto-oncogene Ret, a component of the GDNF receptor complex, persists in human substantia nigra neurons in Parkinson's disease. Brain Res. 792, 207-217.

Worby, C.A., Vega, Q.C., Zhao, Y., Chao, H.H., Seasholtz, A.F., Dixon, J.E., 1996. Glial cell line-derived neurotrophic factor signals through the RET receptor and activates mitogen-activated protein kinase. J. Biol. Chem. 271, 23619-23622.

Wu, X., Zhu, D., Jiang, X., Okagaki, P., Mearow, K., Zhu, G., McCall, S., Banaudha, K., Lipsky, R.H., Marini, A.M., 2004. AMPA protects cultured neurons against glutamate excitotoxicity through a phosphatidylinositol 3-kinase-dependent activation in extracellular signal-regulated kinase to upregulate BDNF gene expression. J. Neurochem. 90, 807-818.

Wu, C., Cui, B., He, L., Chen, L., Mobley, W.C., 2009. The coming of age of axonal neurotrophin signaling endosomes. J. Proteomics 72, 46-55.

Xing, S., Furminger, T.L., Tong, O., Jhiang, S.M., 1998. Signal transduction pathways activated by RET oncoproteins in PC12 pheochromocytoma cells. J. Biol. Chem. 273, 4909-4914.

Yu, T., Scully, S., Yu, Y., Fox, G.M., Jing, S., Zhou, R., 1998. Expression of GDNF family receptor components during development: implications in the mechanisms of interaction. J. Neurosci. 18, 4684-4696. 